\title{
Cost-effectiveness of extended-release niacin/laropiprant added to a stable simvastatin dose in secondary prevention patients not at cholesterol goal in Germany
}

\author{
Galin V. Michailov • Glenn M. Davies • \\ Karl J. Krobot
}

Received: 1 April 2010/Accepted: 24 February 2011/Published online: 5 April 2011

(C) The Author(s) 2011. This article is published with open access at Springerlink.com

\begin{abstract}
Coronary heart disease (CHD) remains the leading cause of death in Germany despite statin use to reduce low-density lipoprotein cholesterol (LDL-C) levels; improving lipids beyond LDL-C may further reduce cardiovascular risk. A fixed-dose combination of extendedrelease niacin (ERN) with laropiprant (LRPT) provides comprehensive lipid management. We adapted a decisionanalytic model to evaluate the economic value (incremental cost-effectiveness ratio [ICER] in terms of costs per life-years gained [LYG]) of ERN/LRPT $2 \mathrm{~g}$ over a lifetime in secondary prevention patients in a German setting. Two scenarios were modelled: (1) ERN/LRPT $2 \mathrm{~g}$ added to simvastatin $40 \mathrm{mg}$ in patients not at LDL-C goal with simvastatin $40 \mathrm{mg}$; (2) adding ERN/LRPT $2 \mathrm{~g}$ compared with titration to simvastatin $40 \mathrm{mg}$ in patients not at LDL-C goal with simvastatin $20 \mathrm{mg}$. In both scenarios, adding ERN/LRPT was cost-effective relative to simvastatin monotherapy at a commonly accepted threshold of $€ 30,000$ per LYG; ICERs for ERN/LRPT were $€ 13,331$ per LYG in scenario 1 and $€ 17,684$ per LYG in scenario 2. Subgroup analyses showed that ERN/LRPT was cost-effective in patients with or without diabetes, patients aged $\leq 65$ or $>65$ years and patients with low baseline high-density lipoprotein cholesterol levels; ICERs ranged from $€ 10,342$ to $€ 15,579$ in scenario 1 , and from $€ 14,081$ to $€ 20,462$ in scenario 2. In conclusion, comprehensive lipid management with ERN/LRPT $2 \mathrm{~g}$ is cost-effective in secondary
\end{abstract}

G. V. Michailov $(\bowtie) \cdot$ K. J. Krobot

Outcomes Research Department, MSD Sharp \& Dohme GmbH,

Haar, Germany

e-mail: galin.michailov@msd.de

G. M. Davies

Health Economic Statistics, Merck \& Co. Inc., Upper Gwynedd, PA, USA prevention patients in Germany who have not achieved LDL-C goal with simvastatin monotherapy.

Keywords Cost-effectiveness - Dyslipidaemia · Extended-release niacin · Hypercholesterolaemia . Laropiprant $\cdot$ Simvastatin

JEL Classification I10

\section{Introduction}

Statin therapy to reduce low-density lipoprotein cholesterol (LDL-C) is the recommended first-line treatment option for German patients with elevated LDL-C [1] and at high risk for cardiovascular events. Despite the use of statins, however, coronary heart disease (CHD) remains the leading cause of death in Germany [2], and the healthcare costs of CHD in Germany in 2006 were the highest in Europe, at $€ 7.9$ billion [3]. Improving lipid parameters beyond the reduction in LDL-C achieved with statins may further reduce the risk of cardiovascular events in patients with dyslipidaemia, because low levels of high-density lipoprotein cholesterol (HDL-C) and elevated triglyceride levels are associated with increased cardiovascular risk [4-7]. In particular, statin therapy does not reduce the increased cardiovascular risk associated with low HDL-C levels [8]. The Dyslipidemia International Study (DYSIS) found that low levels of HDL-C and high triglyceride levels are highly prevalent in Europe [9, 10].

Niacin reduces levels of LDL-C and triglycerides and is the most effective agent for increasing HDL-C levels [11]. Niacin at doses $\geq 2 \mathrm{~g}$, alone or in combination with statins, reduces atherosclerotic $\mathrm{CHD}$ and may reduce coronary events in patients with cardiovascular disease [12-16]. 
However, immediate-release niacin is associated with flushing in more than $90 \%$ of patients who take the drug [17-20] and frequently leads to complete discontinuation of treatment. Extended-release niacin (ERN) is associated with less flushing than the immediate-release niacin formulations [21]. Nonetheless, flushing remains a problem with ERN; treatment must be initiated at a low dose ( $375 \mathrm{mg}$ in Germany; $500 \mathrm{mg}$ in the USA) and complete discontinuation remains common. A retrospective cohort study of primary care patients in Germany found that $50 \%$ of patients treated with ERN alone discontinued therapy after the first prescription, and only $22 \%$ of patients continued treatment for a full year [22]. Moreover, the average maintenance dose was just $840 \mathrm{mg}$, which is below the recommended therapeutic dose range of $1,000-2,000 \mathrm{mg} /$ day.

Acetylsalicylic acid (aspirin) at doses of at least $325 \mathrm{mg}$ is modestly effective in the mitigation of flushing severity $[23,24]$. However, it is infrequently used, must be taken $30 \mathrm{~min}$ before the niacin dose and is not effective as a rescue medication [25, 26]. Niacin-induced flushing is primarily mediated by prostaglandin $\mathrm{D}_{2}\left(\mathrm{PGD}_{2}\right)$, which stimulates the $\mathrm{PGD}_{2}$ receptor-1 (DP1) in the skin [27]. Laropiprant (LRPT) is a potent, once-daily, highly selective DP1 antagonist [28]. Combining LRPT with ERN could therefore inhibit much of the $\mathrm{PGD}_{2}$-mediated flushing, allowing more patients to achieve and maintain clinically effective doses of niacin. In clinical trials in patients with primary hypercholesterolaemia or mixed dyslipidaemia, the ERN/LRPT 2 g combination provided comprehensive lipid management similar to ERN $2 \mathrm{~g}$ alone, but with improved tolerability [29, 30]. ERN/LRPT is contraindicated in patients with significant or unexplained hepatic dysfunction, or with active peptic ulcer disease.

Most patients with dyslipidaemia will receive first-line treatment with a statin; simvastatin is the most commonly prescribed statin in Germany. To illustrate the economic value of add-on ERN/LRPT $2 \mathrm{~g}$ in a German setting, we conducted a cost-effectiveness analysis of ERN/LRPT added to simvastatin monotherapy for the prevention of CHD death, non-fatal myocardial infarction (MI) or non-fatal angina in patients with established CHD not at goal LDL-C (i.e. secondary prevention patients). Patients with established CHD were chosen for the analysis as this group is at a greater risk of cardiovascular events compared with primary prevention patients and is therefore more likely to require treatments in addition to statins to improve lipid parameters such as HDL-C and triglycerides. Three treatments were considered: (1) simvastatin $40 \mathrm{mg}$ monotherapy; (2) addition of ERN/LRPT to simvastatin $40 \mathrm{mg}$ in patients not at LDL-C goal with simvastatin $40 \mathrm{mg}$ alone and (3) addition of ERN/LRPT compared with titration to simvastatin $40 \mathrm{mg}$ in patients not at LDL-C goal with simvastatin $20 \mathrm{mg}$ alone.

\section{Materials and methods}

Model design

A lifetime decision-analytic model was developed to explore the costs and health outcomes associated with the use of ERN/LRPT in combination with simvastatin compared with simvastatin monotherapy. This was based on a previously published model developed to project the long-term benefits and cost of alternative lipid-lowering strategies in patients with hypercholesterolaemia, which has been described in detail elsewhere [31, 32]. Briefly, progression of CHD in secondary prevention patients was modelled with Microsoft Excel and Visual Basic software using a Markov process with an annual cycle between discrete health states (Fig. 1). The individual patient profile data for patients who met the inclusion criteria from the IMS database form the basis for the cohort in the economic analysis. Unlike standard cohort analyses where risk profiles are generated from population averages, these analyses are conducted with the actual patient data. This method allows the transition probabilities to vary from one profile to the next. Patients can either experience a recurrent CHD event (fatal CHD, non-fatal MI or non-fatal angina) or die from non-CHD causes.

The probability of recurrent CHD in patients with established CHD was estimated for each year modelled using published Framingham risk equations from D'Agostino et al. [33]. The impact of treatment was modelled by a mean change in the patient's lipid level (total cholesterol [TC] and HDL-C), which in turn alters the patient's risk of CHD. Because LDL-C is generally calculated from measuring TC and HDL-C, modelling changes in TC and HDL-C alone is sufficient to capture changes in LDL-C. The Framingham risk equations from Anderson and colleagues were used to estimate the probability of fatal CHD, non-fatal MI or non-fatal angina [34]. Because of potential differences in the likelihood of fatal CHD, non-fatal MI or non-fatal angina in primary and secondary prevention patients, the relative rates of these events observed in primary and secondary prevention patients in the Framingham study [33] were used to adjust the allocation of secondary events. Age- and sex-specific non-CHD mortality was calculated by subtracting age- and sex-specific CHD mortality from the all-cause mortality (Table 1). Data for all-cause mortality were obtained from the Federal Health System Information Monitoring website [35] and the Federal Statistics Office [36]. 
Fig. 1 Model flow. CHD, coronary heart disease; MI, myocardial infarction

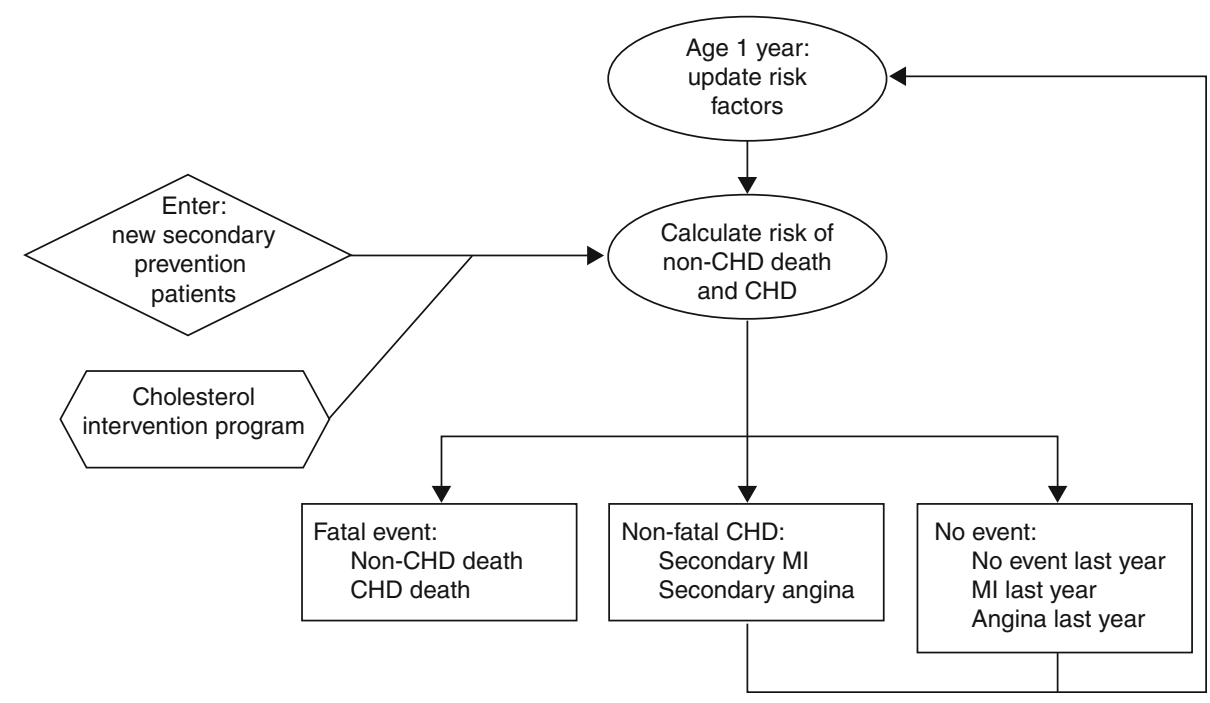

Table 1 Age- and sex-specific non-CHD mortality

\begin{tabular}{lcc}
\hline Age, years & \multicolumn{2}{c}{ Non-CHD mortality per 100,000 participants in 2007} \\
\cline { 2 - 3 } & Men & Women \\
\hline $45-54$ & 367 & 209 \\
$55-64$ & 858 & 475 \\
$65-74$ & 1938 & 1051 \\
$75-84$ & 5081 & 3561 \\
$85-99$ & 12668 & 12102 \\
\hline
\end{tabular}

The cycles were repeated annually until all modelled patients reached an age of 100 years. For each patient profile, lifetime costs and life-years are accumulated over the specified time horizon. The incremental cost-effectiveness ratio is calculated by:

$\frac{\bar{C}_{E}-\bar{C}_{S}}{\bar{Q}_{E}-\bar{Q}_{S}}$

where: $\bar{C}_{E}$ is the average lifetime cost across all patients receiving ERN/LRTP, $\bar{C}_{S}$ is the average lifetime cost across all patients receiving simvastatin $40 \mathrm{mg}, \bar{Q}_{E}$ is the average life-years across all patients receiving ERN/LRTP, and $\bar{Q}_{S}$ is the average life-years across all patients receiving simvastatin $40 \mathrm{mg}$.

\section{Model inputs}

\section{Efficacy of ERN/LRPT and comparators}

The effects on the lipid profile (TC and HDL-C) of addition of ERN/LRPT to simvastatin monotherapy were based on data from a 24-week phase 3 clinical trial in 1,613 patients with primary hypercholesterolaemia or mixed dyslipidaemia, $67 \%$ of whom were receiving a statin at baseline; in this study, total cholesterol decreased by $8.5 \%$ and HDL-C increased by $20 \%$ [30]. The effects of doubling the dose of simvastatin from 20 to $40 \mathrm{mg}$ were based on findings from the Ezetimibe and Simvastatin versus Double Statin Reach New Lipid Treatment Goals (EASEGO) study in 367 patients with type 2 diabetes and/or CHD, in which total cholesterol decreased by $6.6 \%$ and HDL-C increased by $1 \%$ [37]. ERN/LRPT $2 \mathrm{~g}$ added to simvastatin 10, 20 or $40 \mathrm{mg}$ also significantly improved lipid parameters beyond the LDL-C reductions observed with simvastatin alone in a 12-week study in 1,398 patients with primary hypercholesterolaemia or mixed hyperlipidaemia [38].

\section{Patient profiles}

Patients aged 50-80 years with CHD and LDL-C $\geq 100 \mathrm{mg} /$ $\mathrm{dL}$ on simvastatin were selected from a population-based primary care database in Germany (IMS Health) that contains representative data on prescriptions and lipids for $1 \%$ of the German population in 2007 (Table 2). The appropriate International Classification of Disease (ICD) code was used to determine whether patients had CHD or diabetes; patients were also assumed to have diabetes if they had been given a prescription for anti-diabetic medication. Patient baseline characteristics were determined separately for each of the scenarios modelled. Only the earliest recorded TC, LDL-C and HDL-C lipid profile for each patient (not earlier than January 2007) was included, in order to reflect the first possible intervention point for physicians. Incomplete data were available for systolic blood pressure (SBP) and smoker status; the mean SBP was imputed and the proportion of smokers was estimated by randomly assigning values to patients with missing data, based on the data observed. Data on left ventricular hypertrophy were obtained from Cook et al., 2004 [31]. In 
Table 2 Baseline characteristics for patients included in the model

\begin{tabular}{lll}
\hline Parameter & $\begin{array}{l}\text { Scenario } 1 \\
\text { Simvastatin } 40 \mathrm{mg}(n=707)\end{array}$ & $\begin{array}{l}\text { Scenario } 2 \\
\text { Simvastatin 20 mg }(n=886)\end{array}$ \\
\hline Age, years $^{\mathrm{a}}$ & $67.8 \pm 0.3$ & $68.8 \pm 0.3$ \\
$\mathrm{TC}, \mathrm{mg} / \mathrm{dL}$ & $207.3 \pm 1.0$ & $205.6 \pm 1.0$ \\
$\mathrm{LDL}-\mathrm{C}, \mathrm{mg} / \mathrm{dL}$ & $125.5 \pm 1.1$ & $124.9 \pm 0.8$ \\
$\mathrm{HDL}-\mathrm{C}, \mathrm{mg} / \mathrm{dL}$ & $52.3 \pm 0.5$ & $52.7 \pm 0.4$ \\
Triglycerides, mg/dL & $175.7 \pm 4.6$ & $164.7 \pm 2.9$ \\
SBP, mmHg & $138.1 \pm 1.2$ & $135.6 \pm 0.8$ \\
Diabetes, $\%$ & 36.4 & 37.7 \\
Smoker, ${ }^{\mathrm{b}}$ & 24.8 & 20.7 \\
Menopause & Assumed for women aged $\geq 50$ years & Assumed for women aged $\geq 50$ years \\
Left ventricular hypertrophy, $\%^{\mathrm{c}}$ & 35.0 & 35.0
\end{tabular}

Data are shown as mean \pm SE unless otherwise stated

a Age was restricted to 50-80 years, in accordance with the HPS2-THRIVE outcomes study [48]

${ }^{\mathrm{b}}$ Estimated from a subsample of patients

c Not available in IMS Health database. Published echocardiographic or electrocardiographic prevalence estimates [31]

$H D L-C$ High-density lipoprotein cholesterol, $L D L-C$ low-density lipoprotein cholesterol, $S B P$ systolic blood pressure

total, 886 patients receiving simvastatin $20 \mathrm{mg}$ and 707 patients receiving simvastatin $40 \mathrm{mg}$ were considered for evaluation.

\section{Costs and resource use}

All costs were determined from a payer perspective in the German setting (Table 3). Costs of CHD events (fatal CHD, non-fatal MI or non-fatal angina) were for 2004 and were based on data used for the original model [31].

The unit costs of simvastatin 20 and $40 \mathrm{mg}$ and ERN/ LRPT $2 \mathrm{~g}$ were based on the pharmacy retail prices for the largest pack size in Germany in October 2009. In a conservative approach, simvastatin costs were those for the

Table 3 Summary of costs used in the model

\begin{tabular}{lcl}
\hline Parameter & Cost in year 1, $€$ & Cost in year 2, $€$ \\
\hline Angina $^{\mathrm{a}}$ & 4416.00 & 662.00 \\
Non-fatal MI (1st year) $^{\mathrm{a}}$ & 6971.00 & 1046.00 \\
CHD death $^{\mathrm{a}}$ & 3095.00 & NA \\
ERN/LRPT 2 g & 1.76 & NA \\
Simvastatin 20 mg $^{\mathrm{c}}$ & 0.15 & NA \\
Simvastatin 40 mg & 0.33 & NA \\
Laboratory and visit costs $^{\mathrm{d}}$ & 1.00 & NA
\end{tabular}

CHD Coronary heart disease, ERN extended-release niacin, LRPT laropiprant, $M I$ myocardial infarction, $N A$ not applicable

${ }^{\text {a }}$ Cost per year; from Cook et al. [31]

b Cost per day; price as of 8 October 2009

${ }^{c}$ Cost per day; the lowest generic price as of 8 October 2009

${ }^{\mathrm{d}}$ Cost per visit largest pack size and the cheapest available generic formulation [39].

There were no extra physician visit costs to consider with regard to the addition of ERN/LRPT, as physicians in Germany receive a quarterly amount of money per patient regardless of the number of visits within the quarter. Aggregated costs for the measurement of lipid parameters (TC, LDL-C, HDL-C and triglycerides) were $€ 1$ ( $€ 0.25$ each). It was assumed that physicians monitored the whole lipid profiles of the patients. Costs associated with adverse events were excluded (as these were expected to be low), consistent with the approach adopted in similar, previous cost-effectiveness analyses [31, 40]. Utilities were not considered in this analysis, as utilities currently have only a minor role in the determination of drug cost-effectiveness in Germany. Costs and health benefits were discounted at a rate of 3\% per annum, in accordance with guidance from the Institut für Qualität und Wirtschaftlichkeit im Gesundheitswesen (IQWiG).

Model outputs

Cardiovascular events (fatal and non-fatal MI, angina) and life expectancy (life-years gained [LYGs]) were projected over a lifetime (until surviving patients reached an age of 100 years) for all treatments. The accumulated costs were projected over a lifetime and were determined for all treatments studied. Incremental cost-effectiveness ratios (ICERs) were calculated as the incremental cost per LYG for ERN/LRPT compared with simvastatin monotherapy. An ICER of $€ 30,000$ per LYG was assumed as a generally accepted willingness to pay threshold in Germany [41]. 
Sensitivity analyses

\section{Univariate sensitivity analyses}

Univariate sensitivity analyses were performed to test the robustness of the model outputs to changes in discount rates (from base-case $3 \%$ to $0 \%, 5 \%, 7 \%$ or $10 \%$ ), event costs (20\% increase or $20 \%$ decrease), CHD risk (20\% increase or $20 \%$ decrease), cost of ERN/LRPT $2 \mathrm{~g}$ (10\% increase or $10 \%$ decrease), cost of simvastatin (20\% decrease), time until benefit ( 2 years, rather than 1 year), discontinuation of ERN/LRPT owing to flushing (7.4\% of patients) [42] and mean maintenance dose (ERN/LRPT $1.5 \mathrm{~g} /$ day [50\% on $1 \mathrm{~g} /$ day and $50 \%$ on $2 \mathrm{~g} / \mathrm{day}$ ] rather than $2 \mathrm{~g} /$ day).

\section{Subgroup analyses}

The long-term projection of cardiovascular events and mortality, and the cost-effectiveness of ERN/LRPT were determined as described above for several predefined population subgroups: patients with or without diabetes; patients with HDL-C below the norm $(<40 \mathrm{mg} / \mathrm{dL}$ in men and $<45 \mathrm{mg} / \mathrm{dL}$ in women; as defined by the European Society of Cardiology [43]); patients with a TC/HDL-C ratio $\geq 4.5$; and patients aged $\leq 65$ years or $>65$ years.

\section{Results}

Long-term projection of cardiovascular events

In scenario 1, the addition of ERN/LRPT $2 \mathrm{~g}$ to simvastatin $40 \mathrm{mg}$ was associated with an additional undiscounted
0.80 years during the course of a lifetime compared with simvastatin $40 \mathrm{mg}$ alone (Table 4). In scenario 2, adding ERN/LRPT $2 \mathrm{~g}$ to simvastatin $20 \mathrm{mg}$ was associated with an additional undiscounted 0.75 life-years compared with simvastatin $20 \mathrm{mg}$ monotherapy; by contrast, titration of simvastatin 20 to $40 \mathrm{mg}$ added 0.22 life-years (Table 4).

\section{Cost-effectiveness of adding ERN/LRPT to simvastatin}

In the base case for scenario 1 in patients receiving simvastatin $40 \mathrm{mg}$, the projected ICER for adding ERN/LRPT was $€ 13,331$ per LYG compared with simvastatin $40 \mathrm{mg}$ alone (Table 5). Adding ERN/LRPT to simvastatin $40 \mathrm{mg}$ is therefore a cost-effective treatment option relative to the generally accepted threshold of $€ 30,000$ per LYG in Germany.

In the base case for scenario 2, adding ERN/LRPT $2 \mathrm{~g}$ to simvastatin $20 \mathrm{mg}$ was associated with an ICER of $€ 17,684$ per LYG compared with up-titration of simvastatin from 20 to $40 \mathrm{mg}$ day. Thus, adding ERN/LRPT to simvastatin $20 \mathrm{mg}$ monotherapy was cost-effective relative to doubling the dose of simvastatin.

Sensitivity analyses

\section{Univariate sensitivity analysis}

Univariate sensitivity analysis showed that addition of ERN/ LRPT 2 g remained cost-effective (ICER below $€ 30,000$ per LYG) in both scenarios independent of changes in discount rate, event costs, medication costs, the level of baseline CHD risk and mean maintenance dose of ERN/LRPT (1.5 g/day

Table 4 Projected undiscounted life expectancy and life-years gained with addition of ERN/LRPT $2 \mathrm{~g}$ in patients not at LDL-C goal on simvastatin monotherapy

\begin{tabular}{|c|c|c|c|c|c|c|}
\hline & \multicolumn{2}{|c|}{ Scenario $1(n=707)$} & \multicolumn{4}{|c|}{ Scenario $2(n=886)$} \\
\hline & \multirow{2}{*}{$\begin{array}{l}\text { Simvastatin } 40 \mathrm{mg} \\
\text { Remaining } \\
\text { life expectancy, } \\
\text { years }\end{array}$} & \multirow{2}{*}{$\begin{array}{l}\text { ERN/LRPT } 2 \mathrm{~g}+ \\
\text { simvastatin } \\
40 \mathrm{mg} \\
\text { LYG }\end{array}$} & \multirow{2}{*}{$\begin{array}{l}\text { Simvastatin } 20 \mathrm{mg} \\
\text { Remaining } \\
\text { life expectancy, } \\
\text { years }\end{array}$} & \multirow{2}{*}{$\begin{array}{l}\text { Simvastatin } \\
20 \mathrm{mg} \text { titrated } \\
\text { to } 40 \mathrm{mg} \\
\text { LYG }\end{array}$} & \multicolumn{2}{|c|}{ ERN/LRPT $2 \mathrm{~g}+$ simvastatin $20 \mathrm{mg}$} \\
\hline & & & & & $\begin{array}{l}\text { LYG versus } \\
\text { simvastatin } \\
20 \text { mg alone }\end{array}$ & $\begin{array}{l}\text { LYG versus } \\
\text { simvastatin } \\
\text { up-titration }\end{array}$ \\
\hline All patients & 13.28 & 0.80 & 12.82 & 0.22 & 0.75 & 0.53 \\
\hline CHD without diabetes & 14.13 & 0.73 & 13.63 & 0.21 & 0.70 & 0.49 \\
\hline CHD with diabetes & 11.79 & 0.93 & 11.46 & 0.25 & 0.85 & 0.60 \\
\hline Age $\leq 65$ years & 17.62 & 1.25 & 17.75 & 0.37 & 1.22 & 0.86 \\
\hline Age $>65$ years & 11.16 & 0.58 & 10.88 & 0.17 & 0.57 & 0.40 \\
\hline Low HDL-C ${ }^{\mathrm{a}}$ & 12.27 & 0.93 & 12.21 & 0.27 & 0.90 & 0.63 \\
\hline $\mathrm{TC} / \mathrm{HDL}-\mathrm{C}$ ratio $\geq 4.5$ & 12.75 & 0.98 & 12.10 & 0.26 & 0.90 & 0.63 \\
\hline
\end{tabular}

CHD Coronary heart disease, $E R N$ extended-release niacin, $H D L-C$ high-density lipoprotein cholesterol, $L D L-C$ low-density lipoprotein cholesterol, $L R P T$ laropiprant, $L Y G$ life-years gained, $T C$ total cholesterol

${ }^{\text {a }}$ Low HDL-C: men, $<40 \mathrm{mg} / \mathrm{dL}$; women, $<45 \mathrm{mg} / \mathrm{dL}$ 
Table 5 Univariate sensitivity analysis and patient subgroup analysis

\begin{tabular}{|c|c|c|}
\hline & \multicolumn{2}{|l|}{ Cost per LYG, $€$} \\
\hline & $\begin{array}{l}\text { Scenario } 1 \\
\text { ERN/LRPT + simvastatin } 40 \mathrm{mg} \\
\quad \text { vs simvastatin } 40 \mathrm{mg} \text { alone }\end{array}$ & $\begin{array}{l}\text { Scenario } 2 \\
\text { ERN/LRPT + simvastatin } 20 \mathrm{mg} \\
\quad \text { vs simvastatin up-titration }\end{array}$ \\
\hline Base case & 13,331 & 17,684 \\
\hline Time until benefit, 2 years & 14,862 & 19,772 \\
\hline \multicolumn{3}{|l|}{ Discount rate, $\%$} \\
\hline 0 & 11,012 & 14,603 \\
\hline 5 & 15,027 & 19,928 \\
\hline 7 & 16,828 & 22,307 \\
\hline 10 & 19,707 & 26,101 \\
\hline \multicolumn{3}{|l|}{ Event costs, $\%$ change } \\
\hline+20 & 13,245 & 17,593 \\
\hline-20 & 13,418 & 17,775 \\
\hline \multicolumn{3}{|l|}{ ERN/LRPT costs, $\%$ change } \\
\hline+10 & 14,698 & 19,682 \\
\hline-10 & 11,964 & 15,686 \\
\hline \multicolumn{3}{|l|}{$\mathrm{CHD}$ risk, $\%$ change } \\
\hline+20 & 11,599 & 15,326 \\
\hline-20 & 15,940 & 21,234 \\
\hline \multicolumn{3}{|l|}{ Simvastatin costs, $\%$ change } \\
\hline-20 & 13,308 & 18,050 \\
\hline \multicolumn{3}{|c|}{ ERN/LRPT discontinuation rate owing to flushing } \\
\hline $7.4 \%$ & 13,331 & 18,167 \\
\hline Mean maintenance dose, $1.5 \mathrm{~g} /$ day & 11,582 & 15,981 \\
\hline \multicolumn{3}{|l|}{ Subgroup analysis } \\
\hline CHD without diabetes & 15,579 & 20,462 \\
\hline CHD with diabetes & 10,342 & 14,081 \\
\hline Age $\leq 65$ years & 11,783 & 15,680 \\
\hline Age $>65$ years & 14,704 & 19,119 \\
\hline Low HDL-C ${ }^{\mathrm{a}}$ & 10,749 & 14,283 \\
\hline $\mathrm{TC} / \mathrm{HDL}-\mathrm{C}$ ratio $\geq 4.5$ & 10,696 & 14,176 \\
\hline
\end{tabular}

Costs and effects discounted at $3 \%$ per annum

$C H D$ Coronary heart disease, $E R N$ extended-release niacin, $H D L-C$ high-density lipoprotein cholesterol, $L R P T$ laropiprant, $L Y G$ life-year gained

${ }^{\text {a }}$ Low HDL-C: men, $<40 \mathrm{mg} / \mathrm{dL}$; women, $<45 \mathrm{mg} / \mathrm{dL}$

[50\% on $1 \mathrm{~g} /$ day and $50 \%$ on $2 \mathrm{~g} /$ day] rather than $2 \mathrm{~g} /$ day), and discontinuation rates for ERN/LRPT (Table 5). ICERs ranged from $€ 11,012-19,707$ per LYG for scenario 1 and $€ 14,603-26,101$ per LYG for scenario 2.

\section{Subgroup analyses}

Subgroup analyses showed that compared with the overall patient cohort, the projected LYG associated with additional ERN/LRPT treatment in both scenarios was greater in patients aged $\leq 65$ years, and those with diabetes, low
HDL-C or a TC/HDL-C ratio $\geq 4.5$ (Table 5). There were no notable differences between the scenarios.

Adding ERN/LRPT to simvastatin $40 \mathrm{mg}$ in scenario 1 was cost-effective in all of the subgroups analysed (ICER below $€ 30,000$ per LYG). Similarly, adding ERN/LRPT to simvastatin $20 \mathrm{mg}$ was cost-effective compared with titration of simvastatin 20 to $40 \mathrm{mg}$ in scenario 2. Across all subgroups in both scenarios, ICERs remained below $€ 20,462$ per LYG (Table 5). In both scenarios, ICERs tended to be lower than the overall cohort in the subgroups of patients with diabetes, patients aged $\leq 65$ years, patients 
with low HDL-C, and patients with a TC/HDL-C ratio $\geq 4.5$.

\section{Discussion}

Although statins are an established and effective first-line treatment option in Germany for patients with elevated levels of LDL-C [1], treatments to improve other lipid parameters in addition to LDL-C may be needed to further reduce the risk of cardiovascular events in patients with CHD and dyslipidaemia. ERN/LRPT increases HDL-C levels and also reduces LDL-C and triglyceride levels $[30,38]$. Our adapted decision-analytic model showed that addition of ERN/LRPT $2 \mathrm{~g}$ to statin monotherapy was projected to be cost-effective (i.e. ICERs within a commonly accepted cost-effectiveness threshold of $€ 30,000$ per LYG) in two scenarios reflective of clinical practice in Germany; (1) addition of ERN/LRPT to simvastatin $40 \mathrm{mg}$ in patients not at LDL-C goal with simvastatin $40 \mathrm{mg}$ alone; and (2) addition of ERN/LRPT compared with titration to simvastatin $40 \mathrm{mg}$ in patients not at LDL-C goal with simvastatin $20 \mathrm{mg}$ alone.

We modelled the use of ERN/LRPT in two different scenarios using representative patient profiles from a German office-based setting. In scenario 1, ERN/LRPT $2 \mathrm{~g}$ was added to high-dose statin monotherapy (simvastatin $40 \mathrm{mg}$ ), reflecting the aggressive, "fire-and-forget" approach to the treatment of elevated LDL-C that is recommended for secondary prevention of CHD in, for example, the UK [44]. However, this approach leaves considerable scope for further reduction in CHD risk by treatment to increase HDL-C and lower triglycerides, because monotherapy with statins such as simvastatin has limited effects on HDL-C and triglycerides [45]. Our adapted model showed that the improvements in lipid parameters associated with adding ERN/LRPT $2 \mathrm{~g}$ to simvastatin $40 \mathrm{mg}$ were associated with a projected increase in life expectancy of 0.8 years. ERN/LRPT treatment under this scenario was cost-effective, with an ICER of $€ 13,331$ per LYG.

In scenario 2, ERN/LRPT added to simvastatin $20 \mathrm{mg}$ was compared with up-titration of simvastatin 20 to $40 \mathrm{mg}$. This scenario is relevant to German clinical practice because simvastatin $20 \mathrm{mg}$ is the most commonly prescribed dose in Germany. Although titration to simvastatin $40 \mathrm{mg}$ would appear a logical option for patients not at LDL-C goal with simvastatin $20 \mathrm{mg}$, in fact, doubling the dose of a statin yields only a modest (3-7\%) incremental reduction in LDL-C and little or no incremental benefit on HDL-C [46]. Our adapted model showed that comprehensive lipid management with ERN/LRPT added to simvastatin $20 \mathrm{mg}$ provided a projected $0.75 \mathrm{LYG}$, compared with 0.22 LYG with doubling the dose of simvastatin. Addition of ERN/LRPT $2 \mathrm{~g}$ to simvastatin $20 \mathrm{mg}$ was costeffective in this scenario, with an ICER of $€ 17,684$ per LYG compared with doubling the simvastatin dose.

Subgroup analyses showed that adding ERN/LRPT to simvastatin was cost-effective (ICERs below $€ 30,000$ per LYG) in both scenarios for CHD patients with or without diabetes, patients aged $\leq 65$ years or $>65$ years, patients with low HDL-C $(<40 \mathrm{mg} / \mathrm{dL}$ in men and $<45 \mathrm{mg} / \mathrm{dL}$ in women) as defined by the European Society of Cardiology [43] and patients with a TC/HDL-C ratio $\geq 4$.5. ERN/LRPT thus represents a cost-effective treatment option for the prevention of cardiovascular events in secondary prevention patients when added to simvastatin monotherapy at either dose.

The strengths of our analysis include the use of baseline characteristics from actual patients in Germany, although it should be noted that these were not necessarily representative of German patients who received lipid-modifying treatment in specialty care. We also modelled realistic treatment scenarios typical of German clinical practice (initial aggressive LDL-C lowering with simvastatin $40 \mathrm{mg}$, or treatment-to-target with simvastatin $20 \mathrm{mg}$ as initial treatment followed by titration to simvastatin $40 \mathrm{mg}$ for patients not at LDL-C goal). Furthermore, our model was not limited to a fixed time span, but projected cardiovascular morbidity and mortality (and hence costeffectiveness) over a lifetime (up to an age of 100 years). Sensitivity analyses showed that our model was robust to reasonable changes in patient characteristics, and cost and efficacy inputs. In particular, the model was not sensitive to changes in the costs of events; this is important because it indicates that there is no limitation associated with the use in our model of event costs that were not inflated from 2004 values (under the assumption that while some event costs will have increased, others will have decreased).

It is reasonable to consider the cost-effectiveness of ERN/LRPT in the context of other niacin-based treatment options. Our findings are broadly consistent with a costeffectiveness analysis by Roze and colleagues based on the Arterial Biology for the Investigation of the Treatment Effects of Reducing Cholesterol (ARBITER) 2 study and conducted from a French payer perspective; this study concluded that increasing HDL-C levels with ERN 1 g/day in patients with low HDL-C on statin monotherapy was cost-effective for the prevention of CHD events, with an ICER for ERN $1 \mathrm{~g} /$ day added to statin monotherapy of $€ 20,645$ per LYG [40]. It is worth noting that the Roze et al. study included a simple sensitivity analysis to investigate the effects of different levels of compliance (expressed as the proportion of drop-outs) on the costeffectiveness of ERN $1 \mathrm{~g} /$ day. The projected cost-effectiveness of ERN was not markedly altered by drop-out 
rates, with ICERs of $€ 20,645$ per LYG for the base case as compared with $€ 20,454, € 20,225$ and $€ 19,938$ per LYG for drop-out rates of $10 \%, 20 \%$ and $40 \%$, respectively. While drop-outs were associated with a reduction in LYG, this is offset by the reduction in drug acquisition costs. These results suggest that the assumption in our model that patients were fully adherent to the treatment regimen is unlikely to have any notable impact on the projected costeffectiveness of ERN/LRPT. The real-life clinical effectiveness of ERN/LRPT is likely to be greater than that of ERN because of the reduced incidence of flushing and consequent lower rates of medication discontinuation [30].

The main limitation of our model is the use of risk equations $[33,34]$ to predict CHD events based on treatment-induced changes in lipid parameters (in particular, increases in HDL-C); this was necessary because clinical trials evaluating the effects on cardiovascular outcomes of adding ERN/LRPT to statin treatment remain to be completed. We feel that this is a reasonable approach given that clinical trials have demonstrated beneficial effects of niacin on cardiovascular outcomes [12-16] and that ERN/LRPT improves lipid parameters as effectively as other niacinbased treatments such as ERN monotherapy [29, 30]. Furthermore, in a lipid goal attainment study in German patients with CHD, the addition of ERN/LRPT to statin compared with continuation of statin therapy increased the proportion of patients achieving LDL-C goal by $32.7 \%$ in men and $42.8 \%$ in women. Significantly more patients (absolute difference $29.3 \%$ in men and $38.2 \%$ in women) on ERN/LRPT added to statin attained their goal/normal levels for LDL-C, HDL-C and triglycerides [47]. The ongoing HPS2-THRIVE (Treatment of High density lipoprotein to Reduce the Incidence of Vascular Events) study will determine whether ERN/LRPT added to simvastatin with or without ezetimibe improves cardiovascular outcomes in patients with established cardiovascular disease compared with add-on placebo [48]. The use of Framingham risk equations in our model is consistent with treatment guidelines such as those from the US National Cholesterol Education Program Adult Treatment Panel [11] and the Second Joint Task Force of European and other Societies on coronary prevention [49], and with previous cost-effectiveness studies of lipid-modifying treatments [31, 40]. It must be accepted, however, that the Framingham risk equations are based on US population data and may therefore not precisely reflect risk in a German population.

Some additional limitations of our model should also be noted. Patient characteristics such as SBP were assumed to be constant with increasing age; this is a common assumption in studies of this type and inevitably results in an underestimate of CHD risk in the elderly and hence a conservative estimate of the cost-effectiveness of ERN/ LRPT in these patients. Nevertheless, the increase in risk associated with age itself was taken into account in the model, and so, some of the effects of increasing age, as well as changes in other risk factors, would be accounted for indirectly. Incidence of left ventricular hypertrophy was estimated; however, these estimates were based on data from secondary prevention patients with CHD in Germany. Our model also excluded indirect costs and costs of adverse events and assumed perfect adherence to medication; all of these approaches are consistent with previous cost-effectiveness analyses of lipid-modifying treatments [31, 40]. Sensitivity analyses showed that the cost-effectiveness of ERN/LRPT $2 \mathrm{~g}$ was not affected when a discontinuation rate of $7.4 \%$ for ERN/LRPT (the discontinuation rate owing to flushing observed in clinical trials [42]) was included in the model. Finally, the aim of this analysis was to evaluate the cost-effectiveness of ERN/LRPT in Germany, and so, these results cannot necessarily be extrapolated to other countries and settings.

\section{Conclusion}

The results of this analysis indicate that comprehensive lipid management with ERN/LRPT $2 \mathrm{~g}$ is cost-effective in secondary prevention patients in Germany who have not achieved LDL-C goal with simvastatin monotherapy. ICERs for additional treatment with ERN/LRPT were below the commonly accepted cost-effectiveness threshold of $€ 30,000$ per LYG in two scenarios reflective of German clinical practice: (1) addition of ERN/LRPT compared with simvastatin $40 \mathrm{mg}$ alone in patients not at LDL-C goal despite aggressive treatment with simvastatin $40 \mathrm{mg}$ and (2) addition of ERN/LRPT compared with doubling the dose of simvastatin to $40 \mathrm{mg}$ in patients not at LDL-C goal on simvastatin $20 \mathrm{mg}$. Model robustness was confirmed in several univariate sensitivity analyses, for which the ICERs remained considerably below the $€ 30,000$ per LYG threshold. The ongoing HPS2-THRIVE study will assess the potential role of comprehensive lipid management with ERN/LRPT in reducing cardiovascular morbidity and mortality beyond statins.

Acknowledgments All authors participated in the development and writing of the paper and approved the final manuscript for publication. The authors take full responsibility for the content of the paper and thank Dr Richard White and Dr Jenny Handford (Oxford PharmaGenesis ${ }^{\mathrm{TM}} \mathrm{Ltd}$ ) for medical writing support, editorial assistance, and collation and incorporation of comments from all authors. This work was funded by MSD Sharp \& Dohme GmbH, Haar, Germany. GVM and KJK are employees of MSD Sharp \& Dohme, and GMD is an employee of Merck \& Co., Inc., and all are therefore eligible for stock/stock options in the company. 
Open Access This article is distributed under the terms of the Creative Commons Attribution Noncommercial License which permits any noncommercial use, distribution, and reproduction in any medium, provided the original author(s) and source are credited.

\section{References}

1. Hockley, T., Gemmill, M.: European Cholesterol Guidelines Report. www.policy-centre.com/downloads/European-CholesterolGuidelines07.pdf (2007). Accessed 20 November 2009

2. World Health Organization. Mortality country fact sheet 2006 (Germany). http://www.who.int/whosis/mort/profiles/mort_euro_ deu_germany.pdf (2006). Accessed 18 November 2009

3. British Heart Foundation Statistics Website. Health care costs of CHD by country, 2006, EU. http://www.heartstats.org/temp/ ESspTabsp12.2spweb08.xls (2006). Accessed 20 November 2009

4. Austin, M.A., Hokanson, J.E., Edwards, K.L.: Hypertriglyceridemia as a cardiovascular risk factor. Am. J. Cardiol. 81, 7B-12B (1998)

5. McBride, P.: Triglycerides and risk for coronary artery disease. Curr. Atheroscler. Rep. 10, 386-390 (2008)

6. Assmann, G., Schulte, H., von Eckardstein, A., Huang, Y.: Highdensity lipoprotein cholesterol as a predictor of coronary heart disease risk. The PROCAM experience and pathophysiological implications for reverse cholesterol transport. Atherosclerosis 124(Suppl), S11-S20 (1996)

7. Drexel, H., Aczel, S., Marte, T., Benzer, W., Langer, P., Moll, W., Saely, C.H.: Is atherosclerosis in diabetes and impaired fasting glucose driven by elevated LDL cholesterol or by decreased HDL cholesterol? Diabetes Care 28, 101-107 (2005)

8. Jafri, H., Alsheikh-Ali, A.A., Karas, R.H.: Statin therapy does not reduce the increased cardiovascular risk associated with low levels of high-density lipoprotein cholesterol: evidence from randomized controlled trials. Circulation 120, S500 (2009). (Abstract 1423)

9. Gitt, A.K., Kastelein, J.P.P.: Predominant types of dyslipidemia in patients with coronary heart disease treated with statins in Europe and Canada: data from the dyslipidemia international study. Eur. Heart. J. 30(Suppl 1), 591 (2009). (Abstract 3543)

10. Gitt, A.K., Kastelein, J.P.P.: High prevalence of dyslipidemia in 18, 574 patients treated with statins in Europe and Canada: Results of the dyslipidemia international study. Eur. Heart. J. 30(Suppl 1), 303 (2009). (Abstract 1796)

11. NCEP. Third Report of the National Cholesterol Education Program (NCEP) Expert Panel on Detection, Evaluation, and Treatment of High Blood Cholesterol in Adults (Adult Treatment Panel III) final report. Circulation 106, 3143-3421 (2002)

12. The coronary drug project. JAMA 221, 918 (1972)

13. Clofibrate and niacin in coronary heart disease. JAMA 231, 360-381 (1975)

14. Brown, B.G., Hillger, L., Zhao, X.Q., Poulin, D., Albers, J.J.: Types of change in coronary stenosis severity and their relative importance in overall progression and regression of coronary disease. Observations from the FATS Trial. Familial Atherosclerosis Treatment Study. Ann. N. Y. Acad. Sci.748, 407-417 (1995). (discussion 417-418)

15. Brown, B.G., Zhao, X.Q., Chait, A., Fisher, L.D., Cheung, M.C., Morse, J.S., Dowdy, A.A., Marino, E.K., Bolson, E.L., Alaupovic, P., Frohlich, J., Albers, J.J.: Simvastatin and niacin, antioxidant vitamins, or the combination for the prevention of coronary disease. N. Engl. J. Med. 345, 1583-1592 (2001)

16. Canner, P.L., Berge, K.G., Wenger, N.K., Stamler, J., Friedman, L., Prineas, R.J., Friedewald, W.: Fifteen year mortality in
Coronary Drug Project patients: long-term benefit with niacin. J. Am. Coll. Cardiol. 8, 1245-1255 (1986)

17. Knopp, R.H., Ginsberg, J., Albers, J.J., Hoff, C., Ogilvie, J.T., Warnick, G.R., Burrows, E., Retzlaff, B., Poole, M.: Contrasting effects of unmodified and time-release forms of niacin on lipoproteins in hyperlipidemic subjects: clues to mechanism of action of niacin. Metabolism 34, 642-650 (1985)

18. Illingworth, D.R., Stein, E.A., Mitchel, Y.B., Dujovne, C.A., Frost, P.H., Knopp, R.H., Tun, P., Zupkis, R.V., Greguski, R.A.: Comparative effects of lovastatin and niacin in primary hypercholesterolemia. A prospective trial. Arch. Intern. Med. 154, 1586-1595 (1994)

19. Mills, E., Prousky, J., Raskin, G., Gagnier, J., Rachlis, B., Montori, V.M., Juurlink, D.: The safety of over-the-counter niacin. A randomized placebo-controlled trial [ISRCTN18054903]. BMC. Clin. Pharmacol. 3, 4 (2003)

20. Birjmohun, R.S., Hutten, B.A., Kastelein, J.J., Stroes, E.S.: Increasing HDL cholesterol with extended-release nicotinic acid: from promise to practice. Neth. J. Med. 62, 229-234 (2004)

21. Abbott Pharmaceuticals. Niaspan (Niacin extended-release tablets) US prescribing information. http://www.rxabbott.com/pdf/ niaspan.pdf (2005). Accessed 9 November 2009

22. Krobot, K.J., Michailov, G.V., Wagner, A.: Four-year treatment practice with extended-release niacin in Germany: adherence, treatment gaps and daily maintenance dose. Eur. Heart. J. 30(Suppl 1), 590 (2009). (Abstract 3541)

23. Dunn, R.T., Ford, M.A., Rindone, J.P., Kwiecinski, F.A.: Lowdose aspirin and ibuprofen reduce the cutaneous reactions following niacin administration. Am. J. Ther. 2, 478-480 (1995)

24. Whelan, A.M., Price, S.O., Fowler, S.F., Hainer, B.L.: The effect of aspirin on niacin-induced cutaneous reactions. J. Fam. Pract. 34, 165-168 (1992)

25. Trovato, A.T., Norquist, J.M., Rhodes, T., McQuarrie, K., Miller, T.B., Paolini, J.F., Watson, D.J.: The impact of niacin-induced flushing during the first week of therapy in a real world setting. J. Am. Coll. Cardiol. 51, A255 (2008). (Abstract 1019-1150)

26. Kamal-Bahl, S., Watson, D.J., Ambegaonkar, B.M.: Patients' experiences of niacin-induced flushing in clinical practice: a structured telephone interview. Clin. Ther. 31, 130-140 (2009)

27. Cheng, K., Wu, T.J., Wu, K.K., Sturino, C., Metters, K., Gottesdiener, K., Wright, S.D., Wang, Z., O'Neill, G., Lai, E., Waters, M.G.: Antagonism of the prostaglandin D2 receptor 1 suppresses nicotinic acid-induced vasodilation in mice and humans. Proc. Natl. Acad. Sci. U S A 103, 6682-6687 (2006)

28. Sturino, C.F., O’Neill, G., Lachance, N., Boyd, M., Berthelette, C., Labelle, M., Li, L., Roy, B., Scheigetz, J., Tsou, N., Aubin, Y., Bateman, K.P., Chauret, N., Day, S.H., Levesque, J.F., Seto, C., Silva, J.H., Trimble, L.A., Carriere, M.C., Denis, D., Greig, G., Kargman, S., Lamontagne, S., Mathieu, M.C., Sawyer, N., Slipetz, D., Abraham, W.M., Jones, T., McAuliffe, M., Piechuta, H., Nicoll-Griffith, D.A., Wang, Z., Zamboni, R., Young, R.N., Metters, K.M.: Discovery of a potent and selective prostaglandin D2 receptor antagonist, [(3R)-4-(4-chloro-benzyl)-7-fluoro-5(methylsulfonyl)-1,2,3,4-tetrahydrocyclopenta[b]indol-3-yl]-acetic acid (MK-0524). J. Med. Chem. 50, 794-806 (2007)

29. Paolini, J.F., Mitchel, Y.B., Reyes, R., Kher, U., Lai, E., Watson, D.J., Norquist, J.M., Meehan, A.G., Bays, H.E., Davidson, M., Ballantyne, C.M.: Effects of laropiprant on nicotinic acid-induced flushing in patients with dyslipidemia. Am. J. Cardiol. 101, 625-630 (2008)

30. Maccubbin, D., Bays, H.E., Olsson, A.G., Elinoff, V., Elis, A., Mitchel, Y., Sirah, W., Betteridge, A., Reyes, R., Yu, Q., Kuznetsova, O., Sisk, C.M., Pasternak, R.C., Paolini, J.F.: Lipidmodifying efficacy and tolerability of extended-release niacin/ laropiprant in patients with primary hypercholesterolaemia or mixed dyslipidaemia. Int. J. Clin. Pract. 62, 1959-1970 (2008) 
31. Cook, J.R., Yin, D., Alemao, E., Davies, G., Krobot, K.J., Veltri, E., Lipka, L., Badia, X.: Cost-effectiveness of ezetimibe coadministration in statin-treated patients not at cholesterol goal: application to Germany, Spain and Norway. Pharmacoeconomics 22(Suppl 3), 49-61 (2004)

32. Cook, J.R., Yin, D., Alemao, E., Drummond, M.: Development and validation of a model to project the long-term benefit and cost of alternative lipid-lowering strategies in patients with hypercholesterolaemia. Pharmacoeconomics 22(Suppl 3), 37-48 (2004)

33. D'Agostino, R.B., Russell, M.W., Huse, D.M., Ellison, R.C., Silbershatz, H., Wilson, P.W., Hartz, S.C.: Primary and subsequent coronary risk appraisal: new results from the Framingham study. Am. Heart J. 139, 272-281 (2000)

34. Anderson, K.M., Odell, P.M., Wilson, P.W., Kannel, W.B.: Cardiovascular disease risk profiles. Am. Heart J. 121, 293-298 (1991)

35. Das Informationssystem der Gesundheitsberichterstattung des Bundes. http://www.gbe-bund.de/ (2007). Accessed 12 March 2009

36. Statistisches Bundesamt Deutschland. http://www.destatis.de/ jetspeed/portal/cms/ (2007). Accessed 12 March 2009

37. Roeters van Lennep, H.W., Liem, A.H., Dunselman, P.H., Dallinga-Thie, G.M., Zwinderman, A.H., Jukema, J.W.: The efficacy of statin monotherapy uptitration versus switching to ezetimibe/ simvastatin: results of the EASEGO study. Curr. Med. Res. Opin. 24, 685-694 (2008)

38. Gleim, G., Ballantyne, C.M., Liu, N., Thompson-Bell, S., McCrary Sisk, C., Pasternak, R.C., Mitchel, Y., Paolini, J.F.: Efficacy and safety profile of co-administered ER niacin/laropiprant and simvastatin in dyslipidaemia. Br. J. Cardiol. 16, 90-97 (2009)

39. Lauer-Fischer. Lauer-Taxe Online. http://www.lauer-fischer. de/LF/Seiten/Produkte/Lauer-Taxe+online/Lauer-Taxe+online. aspx (2009). Accessed October 2009

40. Roze, S., Ferrieres, J., Bruckert, E., Van Ganse, E., Chapman, M.J., Liens, D., Renaudin, C.: Cost-effectiveness of raising HDL cholesterol by adding prolonged-release nicotinic acid to statin therapy in the secondary prevention setting: a French perspective. Int. J. Clin. Pract. 61, 1805-1811 (2007)

41. Botteman, M.F., Meijboom, M., Foley, I., Stephens, J.M., Chen, Y.M., Kaura, S.: Cost-effectiveness of zoledronic acid in the prevention of skeletal-related events in patients with bone metastases secondary to advanced renal cell carcinoma: application to France, Germany, and the United Kingdom. Eur. J. Health. Econ. (2010). doi:10.1007/s10198-010-0272-0

42. Maccubbin, D., Koren, M.J., Davidson, M., Gavish, D., Pasternak, R.C., Macdonell, G., Mallick, M., Sisk, C.M., Paolini, J.F., Mitchel, Y.: Flushing profile of extended-release niacin/laropiprant versus gradually titrated niacin extended-release in patients with dyslipidemia with and without ischemic cardiovascular disease. Am. J. Cardiol. 104, 74-81 (2009)

43. Graham, I., Atar, D., Borch-Johnsen, K., Boysen, G., Burell, G., Cifkova, R., Dallongeville, J., De Backer, G., Ebrahim, S., Gjelsvik, B., Herrmann-Lingen, C., Hoes, A., Humphries, S., Knapton, M., Perk, J., Priori, S.G., Pyorala, K., Reiner, Z., Ruilope, L., Sans-Menendez, S., Scholte op Reimer, W., Weissberg, P., Wood, D., Yarnell, J., Zamorano, J.L., Walma, E., Fitzgerald, T., Cooney, M.T., Dudina, A., Vahanian, A., Camm, J., De Caterina, R., Dean, V., Dickstein, K., Funck-Brentano, C., Filippatos, G., Hellemans, I., Kristensen, S.D., McGregor, K., Sechtem, U., Silber, S., Tendera, M., Widimsky, P., Altiner, A., Bonora, E., Durrington, P.N., Fagard, R., Giampaoli, S., Hemingway, H., Hakansson, J., Kjeldsen, S.E., Larsen, M.L., Mancia, G., Manolis, A.J., Orth-Gomer, K., Pedersen, T., Rayner, M., Ryden, L., Sammut, M., Schneiderman, N., Stalenhoef, A.F., Tokgozoglu, L., Wiklund, O., Zampelas, A.: European guidelines on cardiovascular disease prevention in clinical practice: executive summary. Eur. Heart J. 28, 2375-2414 (2007)

44. Cooper, A., Nherera, L., Calvert, N., O'Flynn, N., Turnbull, N., Robson, J., Camosso-Stefinovic, J., Rule, C., Browne, N., Ritchie, G., Stokes, T., Mannan, R., Bath, P., Brindle, P., Gill, P., Gujral, R., Hogg, M., Marshall, T., Minhas, R., Pavitt, L., Reckless, J., Rutherford, A., Thorogood, M., Wood, D.: Clinical guidelines and evidence review for lipid modification: cardiovascular risk assessment and the primary and secondary prevention of cardiovascular disease. http://www.guidance.nice.org.uk/CG67/ Guidance/pdf/English (2008). Accessed 22 November 2009

45. Todd, P.A., Goa, K.L.: Simvastatin. A review of its pharmacological properties and therapeutic potential in hypercholesterolaemia. Drugs 40, 583-607 (1990)

46. Jones, P.H., Davidson, M.H., Stein, E.A., Bays, H.E., McKenney, J.M., Miller, E., Cain, V.A., Blasetto, J.W.: Comparison of the efficacy and safety of rosuvastatin versus atorvastatin, simvastatin, and pravastatin across doses (STELLAR* Trial). Am. J. Cardiol. 92, 152-160 (2003)

47. Michailov, G.V., Davies, G.M., Buono, J., Sazonov, V., Krobot, K.J.: Lipid goal attainment in German CHD patients receiving ER-Niacin/Laropiprant added to statin therapy. Clin. Res. Cardiol. 99(Suppl 2), P159 (2010). doi:10.1007/s00392-010-1200-0

48. Clinicaltrials.gov. NCT00461630: Treatment of HDL to reduce the incidence of vascular events HPS2-THRIVE. http://www. clinicaltrials.gov/ct2/show/NCT00461630 Accessed 22 November 2009

49. Prevention of coronary heart disease in clinical practice. Recommendations of the Second Joint Task Force of European and other Societies on coronary prevention. Eur. Heart. J. 19, 1434-1503 (1998) 